\title{
Socioeconomic Determinants of Exposure to Secondhand Smoke Among Pregnant Women
}

\author{
Ahmad Saeed Alghamdi ${ }^{1}$, Hazem Faisal Jokhadar ${ }^{1}$, Ibraheem Mohammed Alghamdi* ${ }^{*}$, Saleh Abdullah \\ Alsohibani ${ }^{1}$, Odai Jamaan Alqahtani ${ }^{1}$, Hayfaa Abdelmageed Wahabi ${ }^{2}$
}

\begin{abstract}
Objectives: Exposure to secondhand smoke (SHS) constitutes major health problems that threaten human health around the world; its adverse effects can lead to serious illnesses in both the pregnant women and the growing fetus. The purpose of this study was to determine the prevalence of SHS among Saudi pregnant women in King Khalid University Hospital (KKUH) and to determine the association between the socioeconomic characteristics of the pregnant women and exposure to SHS.

Materials and Methods: This was a cross-sectional study conducted in the antenatal clinic, KKUH. Data were collected from consecutive women using a predesigned questionnaire addressing the participants' demographics and exposure to SHS status. Results: The prevalence of SHS exposure among pregnant women was $24 \%$. Low maternal education level and being unemployed were associated with more exposure to SHS $(P=0.039)$ and $(P=0.02)$, respectively. There was no association between maternal age, parity and monthly income and exposure to SHS $(P=0.697),(P=0.420)$ and $(P=0.543)$, respectively.

Conclusion: Maternal educational levels and unemployment are associated risk factors for SHS exposure during pregnancy.

Keywords: Passive smoking, Pregnant women, Saudi Arabia, Secondhand smoke, Socioeconomic factors
\end{abstract}

\section{Introduction}

Exposure to secondhand smoke (SHS) constitutes major health problems that threaten human health around the world (1). It is a preventable cause of morbidity and mortality (1). Its adverse effects can lead to serious illnesses in both the pregnant women and the growing fetus (1). During pregnancy SHS exposure can lead to long lasting effects on the infant's respiratory, cardiovascular, central nervous system and other systemic abnormalities (1).

More than 600000 premature deaths every year are caused by exposure to SHS (1). About $40 \%$ of all children, $33 \%$ of male non-smokers and 35\% female non-smokers are exposed to SHS indoors (1). $31 \%$ of the deaths caused by SHS occur in children (1).

In Saudi Arabia, the prevalence of active smoking among males and females ranges according to the age groups with median of $26.5 \%$ and $9 \%$, respectively (2). Although according to previous study, active smoking among pregnant women was low $0.08 \%$, exposure to SHS is reported to be as high as $31 \%(3)$.

The demographic profile of pregnant women exposed to SHS showed that the exposed participants were younger in age, of low parity and lower level of education than non-exposed (3). However, the study did not show the socioeconomic determinants of SHS exposure among Saudi pregnant women (3).

The aims of this study were to determine the prevalence of SHS exposure among pregnant women and to explore the socio-demographic determinants of exposure to SHS among Saudi pregnant women attending the antenatal care clinic in King Khalid University Hospital (KKUH).

\section{Materials and Methods}

This was prospective cross-sectional study designed to investigate the socioeconomic determinants of SHS exposure during pregnancy and to evaluate the pregnant women's knowledge about the harmful effects of SHS.

The study was done in an antenatal outpatient clinic at KKUH, Riyadh, Saudi Arabia. KKUH is a tertiary referral center and includes a neonatal intensive care unit (NICU) and an in vitro fertilization unit. The obstetrics department provides services for 3500 to 4000 deliveries per year. For this study, we invited pregnant women from KKUH antenatal care clinic from October 2013 to March 2014 to participate. The women were invited irrespective of parity or gestational age.

The prevalence rate for SHS exposure during pregnancy was estimated to be $31 \%$ from a recently published study (3). Based on that prevalence the sample size was calculated with $95 \%$ CI and 5\% precision. The minimum sample size needed was 328 participants.

A consecutive sampling technique was used. The inclusion criteria were: pregnant women aged 18 years and older who consented to participate in the study. Exclusion criteria were women who actively smoked and those who declined to participate in the study.

Received 20 December 2015, Accepted 23 February 2016, Available online 10 March 2016

${ }^{1}$ College of Medicine, King Saud University, Riyadh, Kingdom of Saudi Arabia. ${ }^{2}$ Department of Family and Community Medicine, King Saud University, Riyadh, Kingdom of Saudi Arabia.

*Corresponding author: Ibraheem Mohammed Alghamdi, College of Medicine, King Saud University, Riyadh, Kingdom of Saudi Arabia. Tel: +966560460516, Email: ibraheemalghamdi92@gmail.com 
A questionnaire was used for data collection. The questionnaire was designed to assess the demographic characteristics and SHS exposure of the participants (Appendix 1).

The first section of the questionnaire concerned the demographic characteristics of the participants. In this section, closed-ended questions were used in addition to open-ended ones. For instance, open-ended questions were used when asking about age and nationality, while closed-ended questions were used for educational level, marital status, parity, income, and employment.

The next section was designed to determine the prevalence of SHS. We calculated the number of women who were exposed to SHS as a percentage from the total study population. We then determined, as a secondary outcome, the prevalence of active smoking among pregnant women in addition to quantifying the amount of SHS according to the hours of exposure and the number of smokers in the house.

\section{Statistical Analysis}

The statistical analysis for this study was performed using SPSS, version 21.0 (SPSS Inc., Chicago, IL, USA). Descriptive statistics were computed to assess the exposure to SHS during pregnancy. Univariate analysis was applied to assess the association between exposure to SHS and the socio-demographic characteristics by comparing these characteristics on exposed and non-exposed participants in the following; age, parity, educational level, employment, and monthly income. Chi-squared test used to compare dichotomous outcomes (unemployment, monthly income, educational level and parity), while independent $t$ test used to compare continuous variables (age). Statistical significance was determined with a $P$ value of $<0.05$.

\section{Results}

Three hundred sixty-three pregnant women were invited to participate in this study; 328 of whom were found to be eligible, 33 declined to participate and 2 were excluded according to our exclusion criteria.

The mean age of the participants was $29 \pm 7.39$ years, and most were Saudis 303 (92.4\%). Of the participants $234(72.3 \%)$ were multiparous and $139(42.8 \%)$ had a bachelor's degree, while only $2(0.6 \%)$ were illiterate. 113 (34.9\%) were employees. The main mode of transportation was in a private car $165(87.3 \%)$. The majority of the women's families fell under moderate- to high-income levels 243 (81.5\%). The demographic characteristics are shown in Table 1.

Participants were asked to determine the hours of SHS exposure at different locations. The results presented in Table 2. It shows the number of total responses to questions related to SHS exposure at home, at work and while in their transportation vehicle. While 122 (37.3\%) of the respondents reported having active smokers in their residence, only 79 (24\%) were actually exposed, as shown in Table 2. Thirty-four (10.5\%) of the exposed participants were exposed to 5-20 cigarettes per day at home and only $15(4.6 \%)$ were exposed at work. There were 40 (12.3\%) that were exposed at least once or twice a day and 31 (9.5\%) were exposed in their transportation vehicle.

The 122 pregnant women who reported having active smokers at home were compared to the women who were not exposed to SHS. There was no significant association between SHS exposure and age $(P=0.697)$, parity $(P=0.420)$ and monthly income of the family in the study sample $(P=0.543)$.

However, the study showed evidence of association between the exposure of pregnant women to SHS and low educational levels $(P=0.039)$. Employed women were less likely to be exposed to SHS than unemployed women $(P=0.02)$ as shown in Table 3.

\section{Discussion}

We found the prevalence of exposure to SHS among the study participants to be $24 \%$, though $37 \%$ of them have active smokers at home. This prevalence constitutes a health problems to the pregnant women generally and specifically to the growing fetus. According to the literature SHS exposure has been approved to be a carcinogen, it can cause lung cancer and cardiovascular diseases

Table 1. Demographic Characteristics of the Study Participants

\begin{tabular}{|c|c|}
\hline Characteristic & $\begin{array}{c}\text { Saudi Arabia } \\
n=328(\%)\end{array}$ \\
\hline Age & $305^{a}$ \\
\hline Mean (standard deviation) & 29.86 years $(7.4)$ \\
\hline Nationality & 328 \\
\hline Saudi & $303(92.4)$ \\
\hline Non-Saudi & $24(7.3)$ \\
\hline Marital status & 328 \\
\hline Married & $322(98.2)$ \\
\hline Divorced & $6(1.8)$ \\
\hline Number of previous pregnancies & $324^{a}$ \\
\hline Zero & $90(20.8)$ \\
\hline 1-5 times & $204(63.0)$ \\
\hline More than 5 times & $30(9.3)$ \\
\hline Level of education & $325^{a}$ \\
\hline Primary school & $12(3.7)$ \\
\hline Intermediate school & $19(5.8)$ \\
\hline High school & $79(24.3)$ \\
\hline Undergraduate & $48(14.8)$ \\
\hline Bachelor & $139(42.8)$ \\
\hline Postgraduate & $26(8.0)$ \\
\hline Illiterate & $2(0.6)$ \\
\hline Employment & $324^{a}$ \\
\hline Yes & $113(34.9)$ \\
\hline No & $211(65.1)$ \\
\hline Transportation $^{\mathrm{b}}$ & $189^{\mathrm{a}}$ \\
\hline Private car & $165(87.3)$ \\
\hline Taxi & $14(7.41)$ \\
\hline Bus & $10(5.29)$ \\
\hline Monthly income & $298^{a}$ \\
\hline Less than 4999 Saudi Riyal & $55(18.5)$ \\
\hline 5000-9999 Saudi Riyal & $142(47.7)$ \\
\hline 10000-14999 Saudi Riyal & $76(25.5)$ \\
\hline$\geq 15000$ Saudi Riyal & $25(8.4)$ \\
\hline
\end{tabular}


Table 2. Exposure to SHS at Home, at Work, and in Transportation

\begin{tabular}{|c|c|}
\hline Variable & $\begin{array}{c}\text { Saudi Arabia } \\
\mathrm{n}=328(\%)\end{array}$ \\
\hline Any smokers at home & $327^{\mathrm{a}}$ \\
\hline Yes & $122(37.3)$ \\
\hline No & $205(62.5)$ \\
\hline Number of smokers at home & $326^{a}$ \\
\hline $1-2$ & $114(35)$ \\
\hline $3-5$ & $5(1.5)$ \\
\hline None & $207(63.5)$ \\
\hline Number of cigarettes smoked per day & $125^{\mathrm{a}}$ \\
\hline Less than 5 & $25(7.7)$ \\
\hline $5-20$ & $34(10.5)$ \\
\hline More than 20 & $8(2.5)$ \\
\hline I do not know & $58(17.8)$ \\
\hline Number of hours of SHS exposure at home & $325^{\mathrm{a}}$ \\
\hline Less than 1 hour & $38(11.7)$ \\
\hline $1-2$ hours & $18(5.5)$ \\
\hline More than 2 hours & $23(7.1)$ \\
\hline None & $246(75.7)$ \\
\hline Any smokers at work & $220^{\mathrm{a}}$ \\
\hline Yes & $12(4)$ \\
\hline No & $208(64.6)$ \\
\hline Number of smokers at work & $324^{\mathrm{a}}$ \\
\hline $1-2$ & $8(2.5)$ \\
\hline $3-5$ & $7(2.2)$ \\
\hline None & $309(95.4)$ \\
\hline Number of hours of SHS exposure at work & $323^{\mathrm{a}}$ \\
\hline Less than 1 hour & $12(3.7)$ \\
\hline More than 2 hours & $3(0.9)$ \\
\hline None & $304(94.1)$ \\
\hline Frequency of SHS exposure at work per day & $326^{a}$ \\
\hline $1-2$ times & $40(12.3)$ \\
\hline $3-5$ times & $5(1.5)$ \\
\hline More than 5 times & $11(3.4)$ \\
\hline None & $270(82.8)$ \\
\hline Frequency of SHS exposure at work per week & $323^{a}$ \\
\hline $1-2$ days & $10(3.1)$ \\
\hline $3-5$ days & $6(1.9)$ \\
\hline More than 5 days & $1(0.3)$ \\
\hline None & $306(94.7)$ \\
\hline SHS exposure on the transportation vehicle & $326^{\mathrm{a}}$ \\
\hline Yes & $31(9.5)$ \\
\hline No & $295(90.5)$ \\
\hline
\end{tabular}

Abbreviation: SHS, Secondhand smoke.

aTotal number in the variable excluding missing data.

in adults and serious health conditions, such as middle ear infections, pneumonia and bronchitis in infants and children (4). SHS exposure can lead to abnormal newborn length and birth weight (3). The negative effect of the nicotine and cotinine on the development of the placenta and on the function of the oxygen transformation to the fetus is believed to be the cause of such newborn deformities (5-7).

Out of the $37 \%$ (122) who reported presence of active smokers at home, $35.5 \%$ (114) have 1-2 smokers and the rest 3-5 smokers. Our study shows that even though there is high number of consumed cigarettes per day, most of the exposed pregnant reported exposure time of less than
Table 3. Association Between Demographic Characteristics and SHS Exposure

\begin{tabular}{llll}
\hline \multirow{2}{*}{ Characteristics } & \multicolumn{2}{l}{ Exposure to SHS } & \multirow{2}{*}{ P value* } \\
\cline { 2 - 3 } & $\begin{array}{l}\text { Yes } \\
\mathbf{n}(\%)\end{array}$ & $\begin{array}{l}\text { No } \\
\mathbf{n}(\%)\end{array}$ & \\
\hline $\begin{array}{l}\text { Maternal Age (Years) } \\
\text { Parity }\end{array}$ & $29.76 \pm 7.55$ & $29.24 \pm 5.45$ & 0.697 \\
Primigravida & $20(58.8)$ & $14(41.2)$ & 0.420 \\
Multigravida & $56(66.7)$ & $28(33.3)$ & \\
Educational Level & $119^{\mathrm{b}}$ & & \\
High & $44(57.9)$ & $32(42.1)$ & 0.039 \\
Low & $33(76.7)$ & $10(23.3)$ & \\
Employment & & & \\
Yes & $24(52.2)$ & $22(47.8)$ & 0.020 \\
No & $54(73.0)$ & $20(27.0)$ & \\
Monthly Income & $111^{\mathrm{a}}$ & & \\
Low & $19(67.9)$ & $9(32.1)$ & \\
Middle-high & & $32(38.6)$ & 0.543 \\
\hline
\end{tabular}

Abbreviation: SHS, Secondhand smoke.

${ }^{a} P$ value $<0.05$ significant.

${ }^{\mathrm{b}}$ Total number in the variable excluding missing data.

${ }^{c}$ Middle to high income (more than 5000 Saudi Riyal).

d Low income (less than 5000 Saudi Riyal).

Statistical tests included chi-square tests and independent $t$ tests.

one hour, which is inconsistent with other studies that shows the more cigarettes consumed at home, the more hours of exposure reported $(8,9)$. This can be due to either the participants and the active smokers have good knowledge about the harms of SHS exposure and they follow measures to avoid it or it could be due to under reporting by the participants of the real timing of exposure.

Significant association between the low level of education of the pregnant women in the study and the more exposure to SHS is found in this study, which has been showed in the literature (3). Being an unemployed is significantly associated with more exposure to SHS among the participants and this could be due to the less chance to be an employed with low level of education which takes us back to the point of the low level of education is associated with more exposure or it could be due to that the unemployed participants stay at home for longer time which increases the risk of more exposure.

Our study did not find significant association between age, parity and level of monthly income and more exposure to SHS, which is inconsistent with the literature that shows pregnant women with younger age and low parity number are more likely to be exposed to SHS (3).

The study did not measure cotinine level in the pregnant women blood, to see if they were telling the truth about their exposure to SHS. Another limitation was we did not specify whether the participants lived in rural or urban areas, as differences in the cultures and the socioeconomic characteristics have been confirmed in the literature (810). Also we did not assess the knowledge, attitude and behavior of the participants toward SHS exposure.

\section{Conclusion}

One fourth of pregnant women participating in the study were exposed to SHS which constitutes a major public 
health problem. Low educational levels and unemployment are associated with more exposure to SHS. There is urgent need to employ evidence based measures to reduce active smoking and exposure to SHS.

\section{Ethical Issues}

The research was approved by the Institutional Review Board (IRB) of KKUH and approval was granted before starting the study. All participants were asked to sign an informed written consent before the start of data collection.

\section{Conflict of Interests}

Authors declare that there is no conflict of interests.

\section{Financial Support}

Researchers received no financial support.

\section{Acknowledgments}

The authors acknowledge the nurses team in OB/GYN clinic, King Khaled University Hospital, Riyadh, for their aid to interview the pregnant women. In addition, the authors acknowledge Dr. Shaik Shaffi Ahamed, Associate Professor Department of Family \& Community Medicine, College of Medicine, King Saud University, for his aid to do the statistical analysis using SPSS.

\section{References}

1. Worldwide burden of disease from exposure to second-hand smoke. http://www.who.int/ quantifying_ehimpacts/publications/shsarticle2010/ en/

2. Bassiony MM. Smoking in Saudi Arabia. Saudi Med J. 2009;30(7):876-881.

3. Wahabi HA, Alzeidan RA, Fayed AA, Mandil A, Al-Shaikh G, Esmaeil SA. Effects of secondhand smoke on the birth weight of term infants and the demographic profile of Saudi exposed women. BMC Public Health. 2013;13:341. doi:10.1186/1471-2458-
13-341.

4. Bloch M, Althabe F, Onyamboko M, et al. Tobacco use and secondhand smoke exposure during pregnancy: an investigative survey of women in 9 developing nations. Am J Public Health 2008;98(10):1833-1840. doi: 10.2105/AJPH.2007.117887.

5. Vardavas CI, Fthenou E, Patelarou E, et al. Exposure to different sources of second-hand smoke during pregnancy and its effect on urinary cotinine and tobacco-specific nitrosamine (NNAL) concentrations. Tobacco Control. 2013;22(3):194-200. doi:10.1136/ tobaccocontrol-2011-050144.

6. Romani FE, Lanzone AN, Tropea AN, Tiberi FE, Catino S, Apa RO. Nicotine and cotinine affect the release of vasoactive factors by trophoblast cells and human umbilical vein endothelial cells. Placenta. 2011;32(2):153-160.

7. Zdravkovic T, Genbacev O, McMaster MT, Fisher SJ. The adverse effects of maternal smoking on the human placenta: a review. Placenta. 2005;26(suppl A):81-6.

8. Yang L, Tong EK, Mao Z, Hu T-w. Exposure to secondhand smoke and associated factors among nonsmoking pregnant women with smoking husbands in Sichuan province, China. Acta Obstetricia et Gynecologica Scandinavica. 2010;89(4):549-557. doi:10.3109/00016341003713851.

9. Zhang L, Hsia J, Tu X, et al, Stanton B. Peer Reviewed: Exposure to secondhand tobacco smoke and interventions among pregnant women in China: A systematic review. Preventing Chronic Disease. 2015;12. doi:10.5888/pcd12.140377

10. Bhanji S, Andrades M, Taj F, Khuwaja AK. Factors related to knowledge and perception of women about smoking: a cross sectional study from a developing country. BMC Womens Health 2011;11:16. doi:10.1186/1472-6874-11-16.

Copyright (C) 2016 The Author(s); This is an open-access article distributed under the terms of the Creative Commons Attribution License (http://creativecommons.org/licenses/by/4.0), which permits unrestricted use, distribution, and reproduction in any medium, provided the original work is properly cited. 


\begin{tabular}{|c|c|}
\hline Appendix 1 & ( ) 1-2 \\
\hline Demographic characteristics: This section asks about & ( ) 3-5 \\
\hline demographic profile. & ( ) None \\
\hline 1-How old are you? & 12-How many cigarettes do they smoke per day at home? \\
\hline 2-What is your nationality? & ( ) Less than 5 \\
\hline ( ) Saudi & ( ) $5-20$ \\
\hline ( ) Not Saudi & ( ) More than 20 \\
\hline 3-What is your marital status? & ( ) Don't know \\
\hline ( ) Married & 13- How many hours approximately do you expose to \\
\hline ( ) Divorced & cigarettes smoke per day at home? \\
\hline ( ) Widow & ( ) Less than one hour \\
\hline 4-number of previous pregnancies? & ( ) $1-2$ hours \\
\hline ( ) zero & ( ) More than two hours \\
\hline ( ) $1-5$ times & ( ) None \\
\hline ( ) more than 5 times & 14- Do you expose to cigarettes smoke inside the home or \\
\hline 5-What is your highest degree of education? & not? \\
\hline ( ) Primary school & ( ) Yes \\
\hline ( ) Intermediate school & ( ) No \\
\hline ( ) High school & $15-$ Is there any smoker in your work place? \\
\hline ( ) Undergraduate & ( ) Yes \\
\hline ( ) Bachelor & ( ) No \\
\hline ( ) Postgraduate & 16- How many smokers are there? \\
\hline ( ) Illiterate & ( ) $1-2$ \\
\hline 6-Do you work? & ( ) 3-5 \\
\hline ( ) Yes & ( ) None \\
\hline ( ) No & 17-How many hours approximately do you expose to \\
\hline 7-What do you use for transportation? & cigarettes smoke per day at work? \\
\hline ( ) Private car & ( ) Less than one hour \\
\hline ( ) Taxi & ( ) More than two hours \\
\hline ( ) Bus & ( ) None \\
\hline 8- What is the range of your household income? & 18- How many times do you expose to cigarettes smoke per \\
\hline ( ) Less than 4,999SR & day? \\
\hline ( ) 5,000-9,999 SR & ( ) 1-2 times \\
\hline （ ） 10,000-14,999 SR & ( ) 3-5 times \\
\hline ( ) More than 15,000 SR & ( ) more than 5 times \\
\hline 9-do you smoke? Which type? & ( ) None \\
\hline ( ) Cigarettes & 19-How many days do you expose to cigarettes smoke per \\
\hline ( ) Hookah & week at work? \\
\hline ( ) Chewing tobacco & ( ) $1-2$ day/s \\
\hline ( ) I don't smoke & ( ) 3-5 days \\
\hline Exposure to SHS: This section asks about Participant's & ( ) More than 5 days \\
\hline exposure to smoking during daily/weekly/monthly routine. & ( ) None \\
\hline 10-Is there any smoker at your home? & 20- Do you expose to cigarettes smoke in transportation \\
\hline ( ) Yes & vehicle? \\
\hline ( ) No & ( ) Yes \\
\hline 11-How many smokers are there? & ( ) No \\
\hline
\end{tabular}

